Portland State University

PDXScholar

1980

\title{
Interpersonal behavior and depression : an examination of self-descriptions on the Interpersonal check list
}

Douglas Steven Andrews

Portland State University

Follow this and additional works at: https://pdxscholar.library.pdx.edu/open_access_etds

Part of the Clinical Psychology Commons, and the Mental and Social Health Commons Let us know how access to this document benefits you.

Recommended Citation

Andrews, Douglas Steven, "Interpersonal behavior and depression : an examination of self-descriptions on the Interpersonal check list" (1980). Dissertations and Theses. Paper 2966.

https://doi.org/10.15760/etd.2959

This Thesis is brought to you for free and open access. It has been accepted for inclusion in Dissertations and Theses by an authorized administrator of PDXScholar. Please contact us if we can make this document more accessible: pdxscholar@pdx.edu. 
AN ABSTRACT OF THE THESIS OF Douglas Steven Andrews for the Master of Science in Psychology presented Ju1y 21, 1980.

Title: Interpersonal Behavior and Depression: An Examination of Self-Descriptions on the Interpersonal Check List.

APPROVED BY MEMBERS OF THE THESIS COMMITTEE:
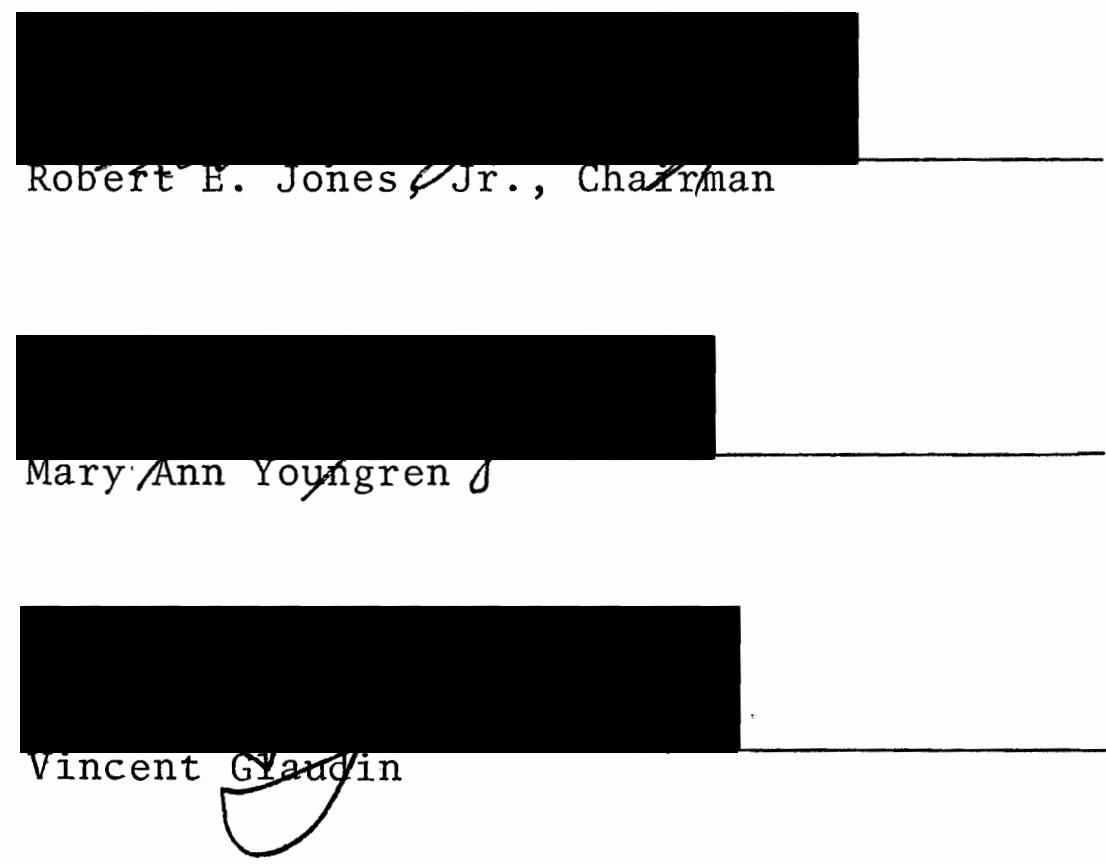

Depressive disorders are recognized as being of long standing clinical and theoretical concern. Early psychoanalytic conceptualizations of depression were later reformulated into theories emphasizing interpersonal manifestations 
of depression, notably passive-dependent oral trends (Chodoff, 1972). Recent research efforts (e.g. Youngren and Lewinsohn, 1980; Weissman and Payke1, 1974; Libet and Lewinsohn, 1973) have explored specific interpersonal behaviors and their relationship to depression. Although some studies have been done utilizing self-report data of interpersonal behavior (e.g. Brown and Goodstein, 1962; Black, 1960), little has been done utilizing self-descriptions of interpersonal traits drawn from a sample of clinically depressed psychiatric outpatients.

Al1 of the data was obtained in an intake battery of tests at a private clinician's office for the depressed sample and at a university psychological clinic for the nondepressed sample.

Two general hypotheses were explored: 1) There is an overall relationship between self-descriptions on an adjective check Iist (Interpersonal Check List, LaForge and Suczek, 1955) and the incidence of depression. 2) There is a relationship between self-descriptions on the Interpersonal Check List (ICL) and severity of depression (measured by the Hamilton Rating Scale for Depression, HRS-D) .

A multiple regression analysis was done with data from a composite sample $(\mathrm{N}=203)$ of depressed $(\mathrm{N}=153)$ and nondepressed, non-psychotic psychiatric outpatients $(\mathrm{N}=50)$. With depression expressed as a dichotomous variable, the data indicated that depressed subjects endorsed significantly 
less frequently than nondepressed subjects items referring to traits of self-respect and assertiveness (ICL octant 2), positive affiliative behaviors (ICL octant 7) and to a lesser extent, endorsed as self-descriptive more frequently than nondepressed subjects, items referring to nurturing parental traits (ICL octant 8). The most significant differentiating ICL scale was octant 2 .

These results are consistent with previous findings noting the relationship between assertiveness and depression.

The second hypothesis was addressed in a multiple regression of ICL scores onto HRS-D scores with data obtained from the depressed sample $(\mathrm{N}=153)$. The results indicated a tendency of these subjects to describe themselves as more passive and dependent (octant 6) and less self-respecting and assertive (octant 2) the more severe the depression. Although statistically significant, the obtained relationship between the ICL and HRS-D scores is minimal and may not endure a replication study.

A perfect confound between depression and setting, different criteria for depressed and nondepressed sample membership and a restricted range in the depressed sample are the major shortcomings of the study. These potential problems are discussed in the context of favorable intervariable correlations and the inherent constraints of research in a clinical setting. 
Recommendations for future research involve addressing discrepancies between objective and subjective descriptions of interpersonal traits, inherent complicating elements of self-report data and further exploration of the nature of self-perceptions of interpersonal behavior in a depressed population. 
INTERPERSONAL BEHAVIOR AND DEPRESSION:

AN EXAMINATION OF SELF-DESCRIPTIONS

ON THE INTERPERSONAL CHECK LIST

by

DOUGLAS STEVEN ANDREWS

A thesis submitted in partial fulfillment of the requirements for the degree of

\author{
MASTER OF SCIENCE \\ in \\ PSYCHOLOGY
}

Portland State University

1980 
TO THE OFFICE OF GRADUATE STUDIES AND RESEARCH:

The members of the Committee approve the thesis of Douglas Steven Andrews presented July 21, 1980.
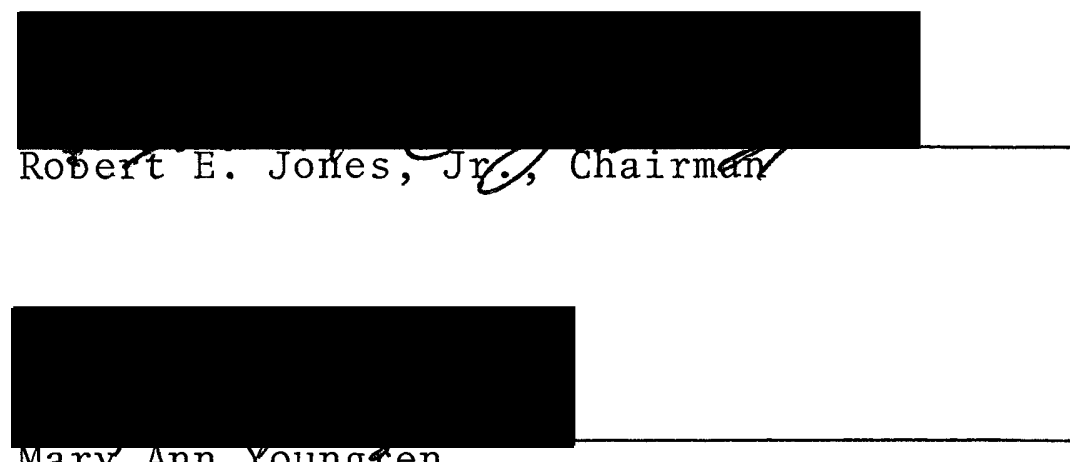
Mary Ann Youngren

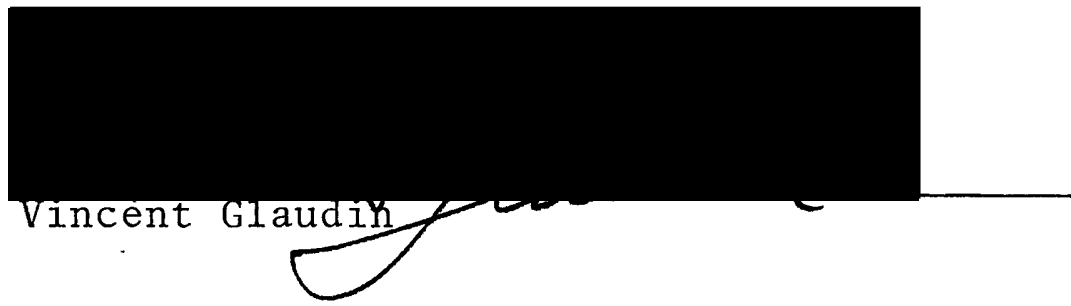

APPROVED :

Robert E. Gones, Jr., Høa, Departmept of Psychology

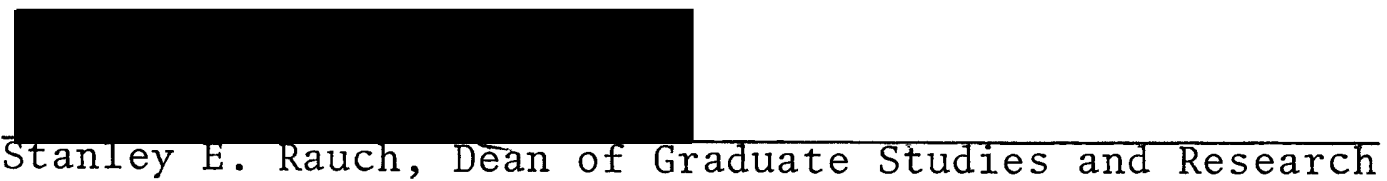




\section{ACKNOWLEDGMENTS}

I would like to express my sincere gratification for the patient guidance and instruction provided by my thesis committee. Robert E. Jones, Jr., for his brainstorming efforts during the initial planning stages and help through the tedious editing at the end. Mary Ann Youngren, for her encouragement and validating support as well as her contributions of research experience in depression. Vince Glaudin, for planting the seed of the original idea of the research, providing the means to carry out the study and remaining flexible and appreciative of the inherent difficulties of clinical research. My appreciation is also extended to the Portland State University Psychological Clinic and personnel for providing data.

Finally, I give thanks for Cindy, whose love and faith in me allowed my efforts to reach fruition. 
TABLE OF CONTENTS

PAGE

ACKNOWLEDGMENTS .

\section{CHAPTER}

I INTRODUCTION • • • • • • • • • • • • •

Defining Depression . . . . . . . 1

Personality and Depression . . . . . 2

Interpersonal Behavior and Depression.

Self-Descriptions and Depression . . . 9

About This Study . . . . . . . . •

Subjects . . . . . . . . . . • •

Procedure . . . . . . . . . . . .

Incidence of Depression and the ICL. .

Severity of Depression and the ICL .

t Test Analyses . . . . . . . • • •

Incidence of Depression and the ICL.

Demographic Variables and Depression .

Severity of Depression and the ICL . 
V SUMMARY AND CRITIQUE . . . . . . . . . . 48

Conclusions. . . . . . . . . 51

REFERENCES • • • • • • . . . . . . . . . . . . 54 APPENDIX

A: INTERPERSONAL BEHAVIOR CIRCLE. . . . . . 59

B： INTERPERSONAL CHECKLIST. . . . . . . . 60

C: DISTRIBUTION OF HRS-D SCORES . . . . . . 61 


\section{LIST OF TABLES}

TABLE

PAGE

I Pearson $r$ Correlations, Means and Standard

Deviations of Independent Variables and Depression . . . . . . . . . . . .

II Pearson $r$ Correlations, Means and Standard

Deviations of Independent Variables and H.R.S. - D. . . . . . . . . . . 


\section{CHAPTER I}

\section{INTRODUCTION}

The National Institute of Mental Health recently released the figure that at any given time there are some eight million people suffering from depression in this country alone, Galton (1979). This figure suggests how pervasive a problem depression currently is, while the extensive literature on melancholia of the mid 1900's is further testament to depression being of long standing clinical concern. In this thesis, the literature on depression and personality is briefly reviewed with an emphasis on interpersonal dimensions of depression. Research is proposed to examine self-described interpersonal traits and their relationship to the depression syndrome.

\section{Defining Depression}

For purposes of this paper, depression is defined as a psychiatric disorder qualitatively distinct from a ordinary and relatively transient lowering of mood frequently encountered outside the psychiatric arena. The symptomatology of a clinical depression can be conceptualized as having four components. 1) Emotional: dejected mood, emo- 
tional blandness, anhedonia and frequent lapses into crying spells; 2) Cognitive: pervasive negative expectations and a tendency towards self blame; 3) Motivational: regressive behavioral tendencies towards passivity and dependency, escapist trends (notably suicide) and avoidance, withdrawal wishes; and 4) Vegetative/Physical: appetite and sleep disturbances and loss of libido (Beck, 1967). Excluded from this study are the qualitatively distinct bipolar depressions. No further categorical distinctions of depression will be utilized (e.g. reactive, neurotic).

\section{Personality and Depression}

Initial theories of depression were primarily derived from speculative conceptualizations based on case studies, a style characteristic of early psychiatric literature.

Early psychoanalytic writings (e.g. Abraham, 1911) maintained that obsessional traits predominated the intermorbid phases of depressives. Later writers (e.g. Titley, 1936; Palmer and Sherman, 1938; Malamud et al., 1941) a1so generally supported the incidence of obsessional traits in a depression prone personality. These later studies however, were criticized on methodological grounds for the use of a questionably valid diagnosis of involutional depression for group definition (Beck, 1967; Chodoff, 1972). Obsessional traits have been enumerated by Freud to include orderliness, parsimony, stubbornness, perfectionism and 
punctuality. Janet has described the obsessive individual as rigid, inflexible, lacking in adaptability, overly concientious, loving order and discipline while also being quite reliable and dependable (Salzman, 1968).

Later psychoanalytic writers pointed more towards orality as a significant predisposing or concommitant personality trait to depression (Abraham, 1916, 1924; Rado, 1928, 1950). As psychoanalytic theorists moved away from an exclusive psychosexual emphasis, the conceptualization of an oral predisposition to depression maintained its importance, taking on, however, more interpersonal connotations. These writers (e.g. Bonime, 1966; Bibring, 1968; Bemporad, 1971) describe orality in terms of exaggerated affectional and supportive needs in a dependent person who almost exclusively relies on others for narcissistic support in the maintenance of their tenuous self-esteem. Bonime (1966) noted how the depressed person can dominate his environment with incessant demands for supportive responses from others. He described depression as a practiced way of relating to others designed to confirm ultimately the negative expectations characteristic of depressive thought processes. Chodoff (1972) has critically reviewed the literature on the depression prone personality and among other summaries notes:

- . It is obvious that these conclusions above are tentative equivocal and hedged about with qualifications and that our current state of 
knowledge about whether and what distinctive premorbid personality characteristics can be associated with clinical depressions leaves a great deal to be desired (p. 671).

Chodoff then suggested the reasons for the current lack of conclusive knowledge involve methodological deficits (i.e., lack of longitudinal studies) and general lack of agreement in defining depressive states and the personality variables assumed to be related to them.

\section{Interpersonal Behavior and Depression}

In the domain of personality theory, Sullivan (1947) is credited with first suggesting the importance of an interpersonal perspective in the conceptualizing of psychopathology. The interest in interpersonal phenomena and their relation to psychopathology (in this case depression) can be considered part of a general movement away from an exclusive focus on the individual and towards theoretical perspectives emphasizing a systems approach, considering the individual in context rather than as an isolated entity. A few isolated examples of this trend would be Bateson's studies of the communication patterns of families of schizophrenic patients (Bateson, 1956), the development of treatment modalities involving the entire family as the "patient" (Satir, 1964; Haley, 1971) and in industrial consultation, a recognition of how the processes inherent in a system's design affects individual performance (Mager and Pipe, 1970). Recent research efforts have been aimed at delineating 
the interpersonal qualities that contribute to, or covary with, depressive disorders. Although psychopathology in general entails an element of social ineptness or inappropriate social behavior, Lewinsohn et al. (1969) have proposed that social skill deficits constitute a significant factor in depression. Working within a social reinforcement model, Libet and Lewinsohn (1973) defined social skill as the ability to maximize response-contingent social reinforcement and minimize behaviors which elicit a punitive social response.

On the basis of observational comparisons of depressed and nondepressed patients in group therapy (Libet and Lewinsohn, 1973; Lewinsohn, Weinstein and Alper, 1970) and in their home environments (Lewinsohn and Schaffer, 1971) several measures of social skill were obtained. The measures obtained quantified the amount of social reinforcement the individual elicited from the environment. These measures were then, by definition, related to the individual's social skills. The results of these studies suggest that an individual is socially skillful if he: 1) is active; 2) is quick to respond; 3 ) is relatively insensitive to an aversive person; 4) does not miss opportunities to react; 5) distributes his behaviors fairly equally among group members; and 6) emits functionally positive reinforcing events. In later studies, (e.g. Libet et al., 1973b), the above noted behavioral criteria successfully differentiated depressed 
and nondepressed persons in small group and home environments. Libet concluded that, as a whole, depressed persons are less socially skillful than nondepressed.

Youngren and Lewinsohn (1980) carried out an industrious multi-trait, multi-method assessment of the functional relationship between depression and problematic interpersonal behaviors. Utilizing a self-report instrument of their own design (Interpersonal Events Schedule, Youngren et a1., 1975), data were derived that significantly distinguished a depressed group from both nondepressed psychiatric and normal groups. The depressed group differed from the controls in that they reported being less comfortable and engaging less frequently in: 1) social activity;

2) giving and receiving positive interpersonal responses; 3) assertive behaviors; and 4) interpersonal events previously found to covary with a positive mood. In addition to these differences in self-report, the depressed subjects' interpersonal style in small group interactions was rated more negatively by both peers and observers.

Weissman and Paykel (1974) successfully differentiated depressed females from nondepressed female controls on the criteria of social adjustment (as operationally defined by the authors). Using interview based rating scales, they found the depressed subjects to be more maladjusted than the nondepressed subjects in all social roles examined (as wife, mother, worker and community member). These same 
authors reported a relationship between the onset of a subject's complaints of depressive symptoms and extensive social dysfunction (interpersonal friction, inhibited communication and submissive dependency). Weissman and Payke1 (1974) additionally noted that often these interpersonal difficulties continued after remission of the clinical depressive symptomatology. This latter finding suggests that the problematic behaviors studied were relatively enduring and may be factors that predispose one to become depressed again.

Ruesch (1962) and Grinker (1964) discussed the depressive personality in terms of communication patterns and general systems theory. These authors pointed out that depressed persons characteristically have a one-sided communication style which is impervious to input or feedback from others. This observation is consistent with cognitive theories of depression which describe depression in part as the maintenance of a closed and rigidly repetitive loop of self-defeating and negative cognitions (Beck, 1967).

Coyne (1976) has argued that an understanding of the interpersonal processes inherent in depression is indispensable to an understanding of depression. Coyne (1976) presented a description of the interpersonal nature of depressive phenomena, noting particularly how depressive symptoms serve as communications that demand affirmation of worth and reassurance of the depressed person's acceptance 
in a relationship. The nondepressed person is forced into a response by the depressed person's demanding and provocative behavior, serving to then shift the responsibility for the depressive experience to others in the social space of the depressed individual.

Initial communications--verbal expressions of helplessness and hopelessness, withdrawal from interaction, slowing, irritability and agitation--tend to engage others immediately and to shift the interactive burden to others (p. 33).

Coyne describes the manipulating and controlling interpersonal tactics of the depressed person who is depicted as inordinately dependent on a relatively narrow social system for maintenance of his/her self-esteem. This characterization is similar to the interpersonal dependency of the oral depressive personality referred to earlier in this paper. What makes Coyne's portrayal of the depression syndrome unique is his assertion that the depressed individual's behaviors are such that they actually elicit counter manipulative behavior from others that meets the negative expectations of the depressed individual. This situation, as described by Coyne, would arise as the depressed person's incessant demands for reassurance eventually induce hostility in others which is then expressed covertly in the desired feedback. This feedback, now ambiguous and ridden with double messages, is interpreted by the depressed individual such to confirm his negative expectations that those about him do not really care for him and are not truly sincere in 
their attempts to reassure him. Stressing again the interactive nature of the depressive syndrome. Coyne notes: "If a depressive spiral develops, it is mutua11y causative . ." (p. 29) .

Ferster (1973) offered a theoretical functional analysis of depression from an operant conditioning model. This analysis emphasizes the intrinsic reinforcers and patterns of interaction in the environment (i.e. interpersonal space) that develop and maintain a depression. Ferster stressed the importance of considering the total behavioral repertoire of the depressed person, noting particularly the behavioral limitations to exhibit positively reinforced behavior and the relatively low frequency of self-initiated behaviors.

\section{Self-Descriptions and Depression}

The use of adjective checklists to research interpersonal traits and depression is an alternative approach to the theoretically speculative or observational studies previously cited. The use of checklists to obtain selfdescriptions has produced data consistent with other findings, as is evidenced in the following reviewed studies.

After coding 206 MMPI profiles, (Minnesota Multiphasic Personality Inventory, Hathaway and McKinley, 1942), Black (1969) summarized the adjectives ascribed to by groups of females sharing similar MMPI profiles. The subjects were 
asked to describe themselves and a randomly selected peer on a modified 140 item checklist (Meeh1 and Hathaway, 1951). The subgroup of individuals with an elevated MMPI D scale $(\mathrm{N}=16)$ described themselves as: genera11y unhappy, selfdissatisfied, self-critical, aloof, moody, quiet, worrying and secretive. These individuals consistently avoided endorsing adjectives with connotations of happiness, hopefullness, optimism and personal strength.

Using the Interpersonal Check List (ICL), (LaForge and Suczek, 1955), to obtain self-descriptions on 200 patients of a psychiatric clinic, Leary (1957) found that people with depressive tendencies on the MMPI tended to describe themselves as skeptical, resentful, bitter, jealous, distrustful as well as lacking in self-confidence and being self-critical. Passive, easily led, shy, dependent and anxious to be approved of were additional interpersonal traits this subgroup endorsed. Generally, Leary found that these individuals described themselves as passive, self-critical and socially inept, choosing either an aloof, skeptical and resentful stance or a meek, docile and unassuming position.

Brown and Goodstein (1962) also used the MMPI to differentiate 46 depressed and nondepressed female clients of a University Counseling Center. Through use of the 300 item Adjective Check List (Gough, 1955) in a revised form (Heilbrun, 1959), these investigators hoped to find correlates of "Hi" and "Lo" scores on the MMPI D scale where "Hi" was 
defined as D> 54 and one of three highest scales, while "Lo" was defined as D< 46 and the lowest scale. Subjects with "Hi" scores on depression described themselves in a manner interpreted as revealing significantly greater needs for deference, abasement and succorance than subjects scoring "Lo" on depression. As a note of caution, the authors suggest the results may also be related to additional MMPI scales found to differ between the "Hi" and "LO" depression groups (e.g. "Lo" D group also scored significantly higher on $\mathrm{K}, \mathrm{Mf}$ and $\mathrm{Ma}$ and lower on Pt than the "Hi" D group). In summary, the social behavior of a depressed individual is characterized as having elements of four dimensions. The first of these includes behaviors that are dependent, helpless, needy, infantile (Bonime, 1966; Seligman, 1974) and motivated by a high need for succorance (Brown and Goodstein, 1962). Secondly, an excessive need for abasement renders a depressed person self-depreciating and such a person additionally tends to provoke punitive, rejecting, depreciating and superior responses from others (Coyne, 1976; Brown and Goodstein, 1962; Leary, 1957). The third is a general subassertive style that has also been associated with depression. A subassertive and depressed individual is defined as one who tends to defer to others, emit fewer spontaneous verbalizations and comes across as modest, indecisive, uncertain, docile, shy, lacking in confidence and perhaps indiscriminately admiring or respect- 
ful of others (Weissman and Payke1, 1974; Brown and Goodstein, 1962; Black, 1969). Lastly and closely related to subassertive traits is a generally manifested deficit in social skills. This would include giving and receiving less positive responses, engaging in less social activity, demonstrating a longer latency of response, more frequently missing opportunities to respond and exhibiting poor communication skills (Youngren and Lewinsohn, 1980; Libet et al., 1973b; Ruesch, 1962).

\section{About This Study}

The present study shares some of the methodological difficulties of previous studies utilizing self-report measures (e.g. Black (1969); Brown and Goodstein (1962); Leary (1957); Weissman and Paykel (1974) and in part, Youngren and Lewinsohn (1980)). A primary confounding factor is reactivity, i.e. an interaction effect between the subject and rater, examiner, clinician and/or researcher. In that there is a large interpersonal dimension to depression, any self-report data can be viewed as a "communication" from the subject to the "other" and therefore subject to the same motives behind many depressive communications. As previously discussed by Coyne (1976) and Bibring (1968), this communication can be characterized as an apparent intent to present themselves in such a light so as to elicit responses to fulfill negative expectations and needs for 
emotional support. Although the self-report data may be subject to motives other than an intention to report accurately one's self-perceptions, previous studies (Youngren and Lewinsohn, 1980) have found self-report data to be one significant factor in differentiating depressed from nondepressed subjects.

One of the difficulties faced in this research was isolating the variable of depression so as to examine the correlates of the depression syndrome. It was reasoned by this examiner that studying data exclusively from a depressed sample without the benefit of a comparison group (i.e. a sampling of patients relatively devoid of depression) would be misleading. However, given the likelihood that many individuals seeking psychological services demonstrate some degree of depression (i.e. lowered mood, anhedonia, loss of motivation), obtaining a "depression free" non-psychotic psychiatric sample was improbable.

The use of a university psychology clinic as a separate setting for collection of the nondepressed sample data allowed sampling from a less severely disabled patient population than what was encountered in the private clinician's office where the depressed sample data was obtained. Although this resulted in an undesirable confound between setting and depression, the advantage of having a comparison group relatively free of depression allowed making observations of the effect of depression on self-descriptions; 
observations that would not be possible without such a comparison group to contrast with the depressed sample data.

What was attempted in this thesis was to further examine the nature of interpersonal behavior in its relationship to depression. Interpersonal behavior and depression have been studied from various conceptual frameworks (see above), but the self-report of interpersonal behavior has received minimal attention. The previous study of Youngren and Lewinsohn (1980) has suggested the efficacy of the self-report in differentiating depressed from nondepressed individuals. Rather than obtaining self-report data of situation specific behaviors and feelings (as did Youngren and Lewinsohn, 1980), this study utilized selfreport data of generalized interpersonal traits. The data employed in this thesis was a structured self-report of interpersonal personality traits measured by the Interpersonal Check List (LaForge and Suczek, 1955).

The Interpersonal Check List (ICL) is a 128 item instrument consisting of descriptive adjectives or phrases with which an individual could describe themselves, their ideal or various others (usually significant family members). The items were originally rationally derived and later empirically revised (LaForge and Suczek, 1955). The Interpersonal Personality System (Leary, 1957) provides the theoretical background for the ICL and posits a circular 
continuum of behavior intersected by two bipolar axes, a hostility-love dimension and a submission-dominance dimension (see Appendix A). The ICL was designed to serve as a "stimulus situation which would be a balanced representation, at various intensities, of each of the 16 hypothesized varieties of interpersonal behavior" (LaForge and Suczek, 1955, p. 98). For purposes of this study, ICL profiles were represented by scores on eight composite scales. The titles corresponding to each of the octants are: 1) managerialautocratic; 2) competitive-narcissistic; 3) aggressivesadistic; 4) rebellious-distrustful; 5) self-effacingmasochistic; 6) docile-dependent; 7) cooperative-overconventional; and 8 ) responsible-hyper-normal.

The validity of the ICL has been demonstrated through correlational studies involving the ICL and the MMPI (LaForge, 1973) and with psychiatric diagnoses (Leary, 1957; LaForge, et al., 1954). Further support of the validity has been provided in the more recent studies of Hogsett, (1972); McDonald, (1968); Briar and Bieri, (1963). Reliability figures for test-retest correlations, as originally published (LaForge and Suczek, 1955) average .78 for octant scores.

There were two general overall hypotheses. First, it was predicted that self-descriptions of the depressed sample would show consistent trends and demonstrate a clear relationship to the occurrence and nonoccurrence of depression. Secondly, that there will be a relationship between scores 
on certain ICL variables and the severity of depression.

The first of these two general hypotheses lead to the following specific hypotheses: that depressed persons are more likely than nondepressed persons to endorse items descriptive of themselves that: 1) depict a withdrawn, resentful, skeptical and overly sensitive person, (octant 4); 2) imply a loss of self-esteem, little self-confidence and a tendency to be hypercritical of self, (octant 5); 3) suggest subassertiveness, excessive dependency and docility, (octant 6). In the negative sense, depressed persons will be expected to less frequently than nondepressed subjects endorse items that: 4) refer to a self-respecting, self-reliant assertive individual, (octant 2) and 5) describe an outspoken, autonomous leader, able to be forceful and give orders, (octant 1).

The second general hypothesis positing a relationship between ICL scales and severity of depression contains the specific hypotheses identical to those enumerated above (i.e. that the more severe the depression, the greater tine tendency to score high on ICL 4,5 and 6 and 1 ow on ICL 2 and 1). 
CHAPTER II

METHODS

\section{$\underline{\text { Subjects }}$}

The samples were drawn from a larger population of psychiatric outpatients. The subjects can be characterized as either of two sorts. The first sample, (D), assumed to represent clinically depressed outpatients, and who form the bulk of the subjects $(N=153)$, are individuals who sought psychiatric services at a private clinician's office with a chief complaint of depressive symptoms. These people were diagnosed as having a primary depressive disorder of at least moderate severity and unipolar type. These subjects were thoroughly physically and psychologically screened for purposes of a separate and independent medication study. Participation in the medication study was voluntary with informed consent. After meeting the clinical criteria for admission to the study, (including minimum scores on the Hamilton Rating Scale for Depression, the Raskin Depression Scale and the Feighner Depression Checklist) the patients were given the promise of treatment for the depression: treatment that would be six weeks in duration and would consist of medication and weekly supportive therapy. These 
individuals were operationally defined as depressed based on the presence of the following symptomatology for a period of at least one month: dysphoric mood, appetite and weight change, sleep disorders, loss of energy, anhedonia, agitation or retardation, self-reproach, guilt, recent change to poor concentration and thinking, and morbidity. Preexisting psychiatric conditions, active alcoholism, severe psychomotor retardation, family history of mania and critical medical illnesses were all criteria for exclusion from the study. The subjects ranged in age from 19 to 64 with an average age of 34 and a standard deviation of 11 . The approximate ratio of female to male clients was $3: 1$.

Only 28 percent of this sample was single with the remaining divided equally among married and divorced. A small number of these subjects had less than a high school education. Individuals with partial college made up the largest number (42 percent), with college graduates ( 9 percent) or those with advanced degrees ( 7 percent) completing the range of educational status.

The second and smaller sample of subjects $(N=50)$ were patients at a university psychological clinic with a chief complaint of other than depressive symptoms (e.g. vocational/ career counseling, anxiety, marital dysfunction, problematic relationships, situational stress, sexual preference confusion). These subjects (GP) are assumed to represent a general psychiatric (non-psychotic) population not suffering 
from a primary depressive disorder. Criteria for inclusion in this sample were the completion of an ICL on an initial visit to the clinic, not verbalizing depression as a chief complaint, scoring less than a $T$ score of 70 on the $D$ scale of the Minnesota Multiphasic Personality Inventory (Hathaway and McKinley, 1942), and having another elevated clinical scale on the MMPI be greater than a $\mathrm{T}$ score of 70 or 1 standard deviation above the D scale. The use of the MMPI D scale to differentiate depressed from nondepressed persons was first introduced by Hathaway and McKinley (1940) and subsequently utilized by Brown and Goodstein (1962), Bodin and Geer (1965), Gravitz (1968) and, in conjunction with other measures, Youngren and Lewinsohn (1980). The age of the subjects ranged from 18 to 65 with an average of 29 and a standard deviation of 10. As in the depressed sample, the ratio of female to male clients was $3: 1$. The majority of these subjects were single (57 percent) and 24 percent were divorced with the remaining 19 percent married. No subjects in this sample had less than a high school education and 35 percent had completed high school, 47 percent had completed some college, and 18 percent were college graduates with no advanced graduate degrees.

\section{$\underline{\text { Procedure }}$}

All of the data in both samples were gathered in the context of an intake battery of tests. For the ICL, a11 
subjects were instructed to check the items on the 1 ist that were descriptive of them. In the GP sample, standard instructions were given during administration of the MMPI. In the depressed sample, scores on the Hamilton Rating Scale for Depression (Hamilton, 1960), were obtained during the initial clinical interview by a licensed psychologist or psychiatrist.

The use of the Hamilton Rating Scale for Depression (HRS-D) in psychiatric research and how it compares to other depression inventories has been critically reviewed (e.g. Bech et al., 1975; Carroll et al., 1973). In general, these reviewers note the capacity of the scale to differentiate levels of depression along a continuum from mild to severe and present favorable figures for rater reliability and validity of the measure. 


\section{CHAPTER III}

\section{RESULTS}

The analysis of the data was threefold, two multipleregression analyses and a set of planned $t$ tests with adjusted degrees of freedom. The first analysis addressed the question: what is the relationship between self-descriptions on the ICL and the occurrence or nonoccurrence of depression? The sample groups GP and D were combined to form a composite sample, $N=203$. Depression was considered as a dichotomous variable based on previously described group membership criteria. ICL variables (eight scales) were introduced in a standard and stepwise fashion in a multiple regression procedure (Kerlinger and Pedhazur, 1973). Given the exploratory nature of this investigation, all ICL variables as well as the demographic variables of age, sex, marital and educational status were considered as potential predictor variables in the attempt to predict the criterion variable-depression. However, based on previous findings, it was predicted that octants 4,5 , and 6 would be positively correlated with the occurrence of depression and octants 1 and 2 would be negatively correlated with the occurrence of depression. No predictions were advanced for the demographic variables. 


\section{Incidence of Depression and the ICL}

In the regression of ICL scales and demographic data onto the dichotomous variable of depression, the predictor variables ICL scales 2,7 and marital status were consistently found to contribute significantly to the prediction of the criterion variable--depression. This was the case in all possible combinations of variables, and when considered in a standard or stepwise format.

In examination of the intervariable correlations one notes negative correlations significant at $\alpha<.05$ between depression and ICL scale $2(\underline{r}=-.3543), 1(\underline{r}=-.2523)$, $7(\underline{r}=-.2271)$ and marital status-single $(\underline{r}=-.3043)$. Age and marital status-married held positive correlations with depression significant at $\alpha<.05$ with respective correlations of $\underline{r}=-.2144$ and $\underline{r}=.1982$.

Correlations among ICL scales ranged from a high of $\underline{r}=.6150$ for ICL 7 with 8 to a low of $\underline{r}=.0306$ for ICL 2 with 6. Notably, ICL scales 2 and 7 had a nonsignificant simple correlation of $\underline{r}=.1683$. Correlations among ICL scales were consistent with the theory and internal structure of the test which assumes that adjacent scales contain items most similar and will be more positively correlated than scales further apart on the circle. This relationship among ICL scales and the traits assumed represented in the scales is represented graphically in the ICL diagram in 
Appendix A.

Marital status-single had no significant simple correlations with any of the ICL scales. The correlation of marital status-single with the discriminating ICL scales 2 and 7 was minimal $(\underline{r}=.0862 ; \underline{r}=.0098$, respectively). Age, as a variable, did not correlate significantly with ICL $2(\underline{r}=.0481)$ and ICL $7(\underline{r}=.0243)$. Marital statusmarried correlated with ICL $2(\underline{r}=-.1671)$ and with ICL 7 $(\underline{r}=-.0490)$ neither of which is significant at the .05 level. Table I includes a complete listing of all intervariable correlations, significance levels and means and standard deviations where applicable.

ICL variables were submitted to a stepwise regression analysis with only significant variables in the equation $(\underline{R}=.4181)$. This multiple correlation is significant $(F=14.05 ; \mathrm{d} f=3 / 199 ; \alpha<.01)$. Further analysis reveals that 17 percent of the variance of identified depression can be accounted for by a linear combination of an individual's score on ICL scales 2,7 and 8 . The regression was not continued beyond these three variables as no other ICL scale could account for significant variance of depression in an equation already containing scales 2,7 and 8 . Analysis of the B weights associated with scales 2,7 and 8 reveals them all to be significant $(F=27.05, F=11.85$, $F=4.92 ; \mathrm{df}=1 / 199 ; \alpha<.01)$ respectively. The regres sion equation for $r$ aw scores is: $Y^{\prime}=1.09-.0581 X_{2}$ 


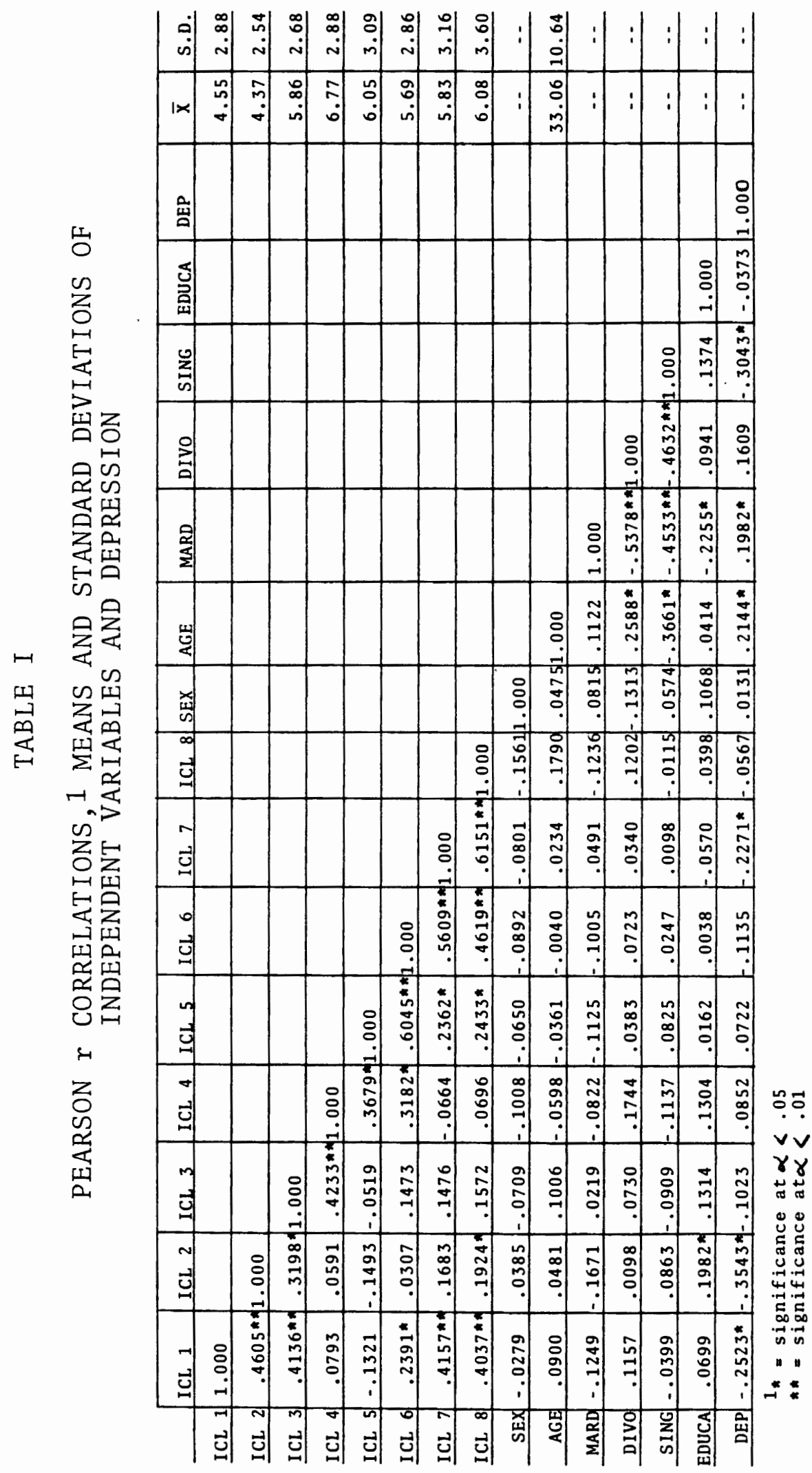


$-.0385 \mathrm{X}_{7}+.0218 \mathrm{x}_{8}$ and for $\mathrm{Z}$ scores is $\mathrm{z}_{\mathrm{y}^{\circ}}=-.3420 \mathrm{z}_{\mathrm{x}_{2}}$ $-.2818 \mathrm{z}_{\mathrm{x}_{7}}+.1825 \mathrm{z}_{8} \cdot$

In summary, ICL scale 2 was found to be significant in the prediction of membership in a depressed or nondepressed sample. The negative correlation of ICL 2 and depression and the clear significance of scale 2 in differentiating depressed from nondepressed subjects indicates a tendency for depressed persons to select phrases referring to a self-reliant, selfrespecting competitive individual as self-descriptive less frequently than nondepressed persons. Once the portion of variance of the depression variable that could be accounted for by scale 2 was taken into account, the contribution of other ICL scales to the prediction was relatively minimal. ICL scales 7 and 8 showed some capacity for differentiating depressed and nondepressed subjects. These results suggest that depressed persons will tend to avoid describing themselves with terms referring to positive affiliative interpersonal behaviors (scale 7) and, to a lesser extent, will be more likely to attribute to themselves nurturing, parental behaviors as the "one who tries to take care of others" (scale 8).

Demographic variables of marital status and sex were considered as separate variables and scored in a dichotomous fashion (i.e. married, divorced, single and sex were scored "0", "1" with a " 0 " indicating not married, a "1" indicating married; a "0" indicating not divorced, a "1" indicating 
divorced, similarly for single. In sex, "0" was scored as female, "1" as male). Dichotomizing these variables allowed interpretable correlation coefficients and was consistent with the criterion variable, depression, since it was expressed as a dichotomy. When demographic variables are considered in a stepwise regression independent of ICL scales, a significant multiple correlation is obtained if the equation only contains significant variables $(\underline{R}=.3043 ; F=$ $18.88 ; \mathrm{df}=1 / 185 ; \alpha<.01)$. The demographic variable, single is entered in the equation first and accounts for 9 percent of the variance of depression scores. With "single" already in the equation, no other demographic variable can contribute significantly to the prediction of depression. The next variable to enter the equation would be age which has a nonsignificant $B$ weight $(F=2.52 ; \mathrm{df}=2 / 185)$.

The raw and $Z$ score equations are: $Y^{\prime}=.8356$ $-.2918 X_{\text {SING }}$ and $z_{y^{\prime}}=-.3043 Z_{X_{\text {SING }}}$ respectively.

In this sample of outpatients, marital status is the only demographic variable that differed significantly between the depressed and nondepressed groups. This significant difference was apparent in a regression analysis when all measured demographic variables were considered simultaneously and partial correlations were considered.

Al1 8 ICL scales and demographic variables of age, sex, educational and marital status were entered into a stepwise regression analysis, with a significant multiple 
correlation obtained $(\underline{R}=.4799)$ if the regression is halted with only significant variables in the equation. This multiple correlation is clearly significant $(F=18.26$; $\mathrm{df}=3 / 183 ; \alpha<.01)$. A linear combination of ICL scales 2, 7 and marital status-single can account for 23 percent of depression when expressed as a dichotomous variable where 1 and 0 represent membership in a depressed and nondepressed sample, respectively.

Analysis of the B weights associated with ICL scale 2, scale 7 and marital status-single revealed all Bs to be respectively significant $(F=20.81, F=6.97$ and $F=18.06$; $\mathrm{df}=1 / 183 ; \alpha<.01)$.

The equations for raw scores and $z$ scores respectively, are: $Y^{\prime}=1.19-.0512 X_{2}-.0237 X_{7}-.2652 X_{\text {SING }}$ and $Z_{y^{\prime}}=$ $-.3012 z_{x_{2}}-.1737 z_{x_{7}}-.2766 z_{X_{\text {SING }}}$

\section{Severity of Depression and the ICL}

The second analysis addressed the stated hypothesis that self-descriptions on the ICL are related to the severity of depression. The data obtained from the depression sample (D) with an $\mathrm{N}=153$ was used in this analysis. Scores on the Hamilton Rating Scale for Depression in this sample ranged from 13 to 37 with a mean of 25.27 and a standard deviation of 5.27. Appendix $C$ is a graphic display of the distribution of HRS-D scores. This sample of depressed subjects was considered to represent a spectrum of depression 
from mild/moderate to severe. As one might expect when sampling from a population of clinically depressed subjects, the range was somewhat restricted. Kenesevich et a1. (1977), Bech et al. (1975) and Carroll et a1. (1973) suggest norms for severity of depression and scores on the HRS-D with approximate cut offs scores of 12 for mild, 18 for moderate and over 30 indicating severe depression.

In a multiple regression analys is (Kerlinger and Pedhazur, 1973) the predictor variables of ICL scores were regressed on the criterion variable-depression, as scored on the HRS-D. In keeping with the exploratory nature of this investigation, all eight ICL scales and demographic variables were considered and introduced in both a standard and stepwise fashion. The same octants of $4,5,6,1$ and 2 were predicted to account for the greatest amount of variance of the depression scores. Again, no predictions were made for the demographic variables.

In the regression of ICL scales and demographic variables onto scores on the Hamilton Rating Scale for Depression, only a small portion of the variance of HRS-D scores could be accounted for. None of the demographic variables were significant predictors, even when considered independent of ICL scales. The ICL scales 6 and 2 were the only variables that correlated significantly with severity of depression.

By examining the correlation matrix, it is apparent 
that ICL scale 6 is the only predictor variable producing a significant simple correlation with the criterion variable HRS $-D(\underline{r}=.2150$, significant at $\alpha<.05)$. ICL scales 4,5 and 2 have moderate correlations with HRS-D, $(\underline{r}=.1750$, $\underline{r}=.1709$ and $\underline{r}=-.1421$ ) respectively. Intercorrelations among ICL variables ranged from a moderate correlation between scales 5 and $6(\underline{r}=.6330)$ to a relatively low correlation between 6 and $2(\underline{r}=.005)$. Table II includes a complete listing of intervariable correlations, significance levels and means and standard deviations where applicab1e.

ICL variables were considered in a stepwise regression analysis in the prediction of HRS-D scores $(\underline{R}=.2571)$. This multiple correlation figure is generated if the regression is halted at the step where variables not yet in the equation would not be significant if brought in. Although this $R$ is statistically significant $(F=5.309 ; \mathrm{df}=2 / 150$; $\alpha<.01$ ), only 6 percent of the variance of HRS-D scores is accounted for by the linear combination of ICL scales 6 and 2. The $B$ weights associated with scales 6 and 2 are respectively significant at $\alpha<.01$ and $\alpha<.05$ (F $=7.374$ and $F=3.195 ; \mathrm{d} f=2 / 150)$.

The standard error of the predicted HRS-D scores (i.e. $\mathrm{Y}^{\prime}$ ) is $=5.16$ while the HRS-D scores have a standard deviation of 5.28. This nominal difference between the standard errors of the $Y$ and predicted $Y^{\prime}$ scores would not 


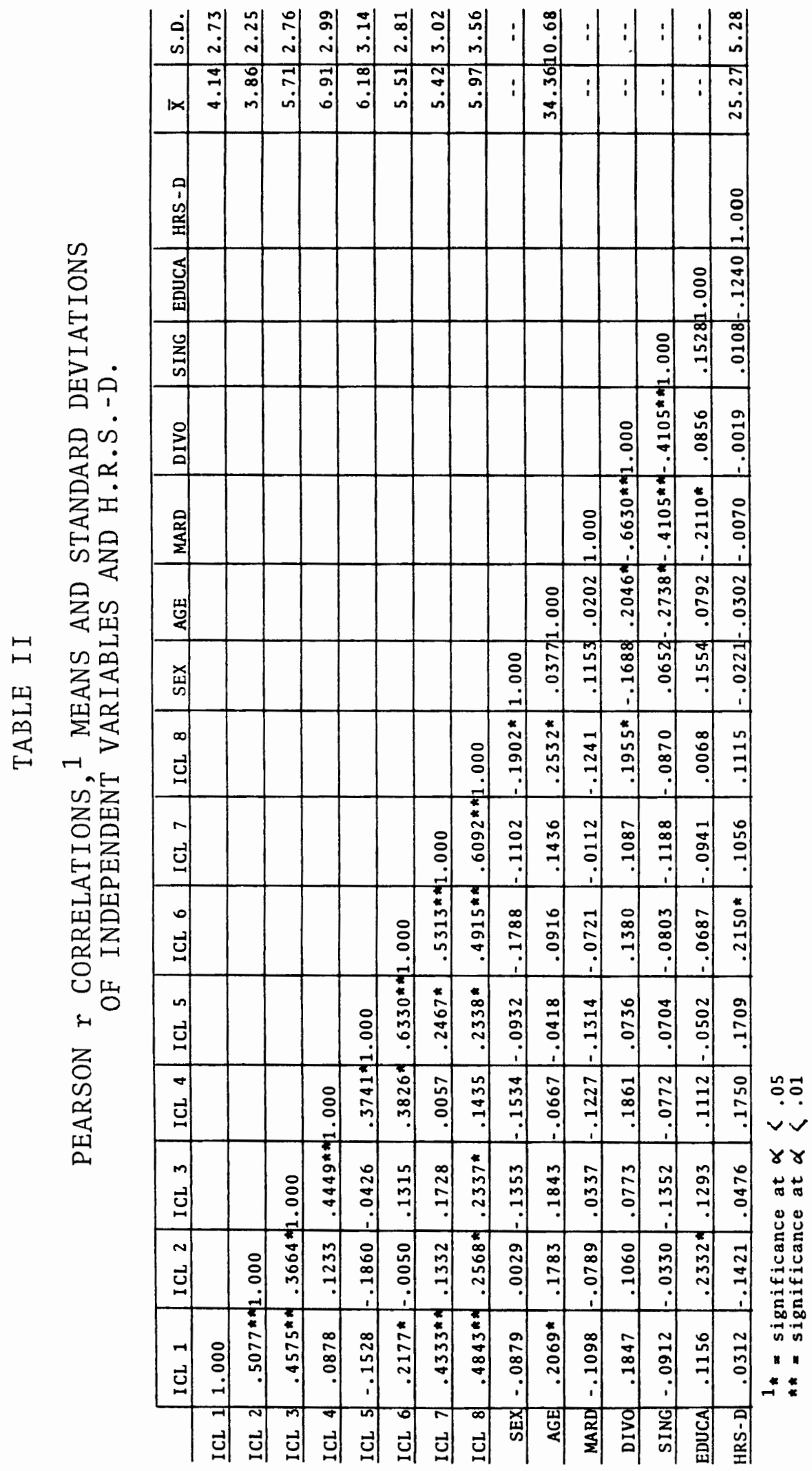


have been increased appreciably with the addition of more ICL scales in the equation. That is, the best prediction of HRS-D scores is from the linear combination of ICL scales 6 and 2 . This prediction, however, has an error factor almost equal to the random variance of the HRS-D scores.

The regression equation for raw scores is: $Y^{\prime}=24.3318+.4029 X_{6}-.3313 X_{2}$. The equation for $Z$ scores is: $z_{y^{\prime}}=.2142 z_{X_{6}}-.1410 z_{X_{2}}$.

When the demographic variables: age, sex, educational and marital status are considered alone in a stepwise regression on HRS-D scores, the first predictor brought into the equation is educational status. The obtained multiple $\mathrm{R}(\underline{\mathrm{R}}=.1240)$ is nonsignificant $(F=2.356$; $\mathrm{df}=1 / 151)$. Further analysis indicates that the variables of age, sex or marital status would not be significant in the prediction of HRS-D.

A stepwise regression of ICL variables and demographic variables onto HRS-D scores had results identical to a regression analysis only including ICL variables. F values associated with any of the partial correlations of the demographic variables after significant ICL variables are in the equation did not reach significance levels.

\section{$t$ Test Analyses}

The final analysis was a comparison of the ICL pro- 
files of the depressed sample (D), $N=153$ and nondepressed general psychiatric sample (GP), $N=50$. The ICL variables $1,2,4,5,6$ and 8 were contrasted with a t test procedure with adjusted significance levels per Dunn's (1961) procedure (Kirk, 1968). This analysis addressed the first general hypothesis that depressed and nondepressed samples differ significantly in their self-ascribed interpersonal traits.

The ICL scales 2,1 and 7 were the only scales that achieved a $t$ value greater than the critical value of $t=2.79$ for the overall significance level of $\alpha<.05$. The respective $t$ values associated with scales 2,1 and 7 were: $t=-5.37, t=-3.70$ and $t=-3.31 ; \mathrm{d} f=201$. The $t$ values associated with the remaining scales $4,5,6$ and 8 predicted to be significantly different are as follows: $t=1.21, \alpha=.227 ; t=1.03, \alpha=.306 ; t=-1.62, \alpha=$ .107 ; and $t=-.80, \alpha=.442$, respectively.

When the depressed and nondepressed samples were contrasted on demographic variables with multiple $t$ tests, they were found to differ significantly on age and marital status. The obtained $t$ values were, as a group, significant at $\alpha<.05(t=3.11, t=2.87, t=-4.53 ; \mathrm{df}=201)$. These results indicate that the depressed and nondepressed samples were markedly different on some demographic variables. Although there was a comparable male-female ratio in each sample and comparable educational status, the 
depressed sample did tend to be older $\left(\overline{\mathrm{X}}_{\mathrm{DEP}}=34 \mathrm{YOA}\right.$ $\overline{\mathrm{X}}_{\mathrm{NDEP}}=29 \mathrm{YOA}$ ) and were more likely to be other than marital status-single (i.e., married or divorced).

As noted earlier, these demographic variables that were significantly different between the depressed and nondepressed samples correlated minimally with ICL variables. 
CHAPTER IV

\section{DISCUSSION}

Before further discussing the results and possible conclusions of the findings, it is necessary to briefly discuss the interaction among depression, the demographic variables, the setting and the ICL scales. In the effort to obtain a nondepressed psychiatric sample and due to the constraints of data accessibility, data on the nondepressed sample were obtained in a university psychology clinic. Although the university psychology clinic serves the general community, it is a distinctly different setting from the psychiatric office in a medical complex where the depressed sample data was obtained. This sampling process resulted in a perfect confound between setting and depression. Some of the nature of this confound is reflected in significantly different demographic measures, specifically, age and marital status.

A reasonable concern would be that any differences on the ICL self-descriptions could likely be reflecting the difference between the samples on the variables of age or marital status. Were this so, such differences on the ICL would not necessarily reflect a difference due to the presence or absence of depression. Examination of the 
correlation coefficients for the ICL scales of interest (significant scales 7 and 2) and the significant demographic variables reveal a minimal relationship.

The Pearson $r$ coefficients reflecting the correlations between ICL scales 2,7 and demographic variables age and marital status are all nonsignificant. The figures range from $\underline{r}=-.1671$ for $\mathrm{ICL} 2$ and married to $\underline{r}=.0098$ for ICL 7 and single. Such low Pearson $r$ values reveal a minimal interaction between ICL 2,7 and age or marital status as measured in this sample.

Given these data, one can safely conclude that the significant differences between the depressed and nondepressed samples on ICL 2 and 7 are not merely redundant and mirroring a difference between the samples already reflected in age and marital status. It appears that differences on the ICL scales 2 and 7 between the depressed and nondepressed samples is actually reflecting a difference due to the presence or absence of depression and not due to age or marital status.

\section{Incidence of Depression and the ICL}

The data suggest that there is a reliable relationship between ICL self-descriptions and the incidence of depression. The significant simple correlations of the ICL scales 1,2 and 7 with the depression variable and particularly the significant multiple $R$ obtained from a 
linear combination of the scales 2,7 and 8 allow rejection of the null hypothesis, (Ho: $\left.\rho_{y \cdot k}=0\right)$.

of the ICL scales $1,2,4,5$ and 6 for which predictions were made, only scale 2 turned out to be significant in the regression analysis. As predicted, scale 2 was negatively correlated with depression and strongly differentiated the depressed and nondepressed samples. This result suggests that the depressed people in this sample avoided using terms characterized by "competitive narcissistic" qualities to describe their interpersonal traits, while nondepressed persons found these terms self-descriptive. The items in scale 2 , listed as to reflect the continuum from a mild to an extreme amount of the trait are as follows: able to take care of self, self-respecting, businesslike, independent, likes to compete with others, self-confident, can be indifferent to others, self-reliant and assertive, selfish, boastful, thinks only of himself, proud and self-satisfied, shrewd and calculating, somewhat snobish, cold and unfeeling, egotistical and conceited.

Scale 1, which was also predicted to be negatively correlated with the occurrence of depression, was, in fact, negatively correlated with depression. It would appear that, given the high correlation between scales 1 and 2 $(\underline{r}=.46)$, the discriminating capability of scale 1 was diminished once the overlap with scale 2 was taken into account. Notably however, there apparently was a tendency 
for a differential response on scale 1 between the samples. Depressed people did not select as self-descriptive, items descriptive of an outwardly power oriented, managerial and dominant individual; an individual likely to possess good leadership skills and be admired by and looked up to by others.

Contrary to predictions, the scales loaded with passive, self-effacing and dependent interpersonal trends (4,5 and 6) did not discriminate depressed from nondepressed samples. The reasons for nonsignificant results are not clear but, one explanation of similar responses on these scales between the depressed and nondepressed samples may have to do with attitudes or motivations specific to the context in which the data were obtained. One might speculate that self-depreciation and self-dissatisfaction, as well as a general hopeless and helpless attitude, may be a common phenomenon shared by many individuals who find their lives in disarray and are seeking professional help. The often observed "plea for help" may be operative here, motivating both depressed and nondepressed subjects to present themselves as needy and dependent.

Before concluding that there is not a relationship between depression and the traits of passive-dependency and self-depreciation (ICL 4, 5 and 6), it is noted that the nonsignificant results for scales 4,5 and 6 run contrary to previous findings (e.g. Coyne, 1976; Brown and 
Goodstein, 1962; Black, 1969). Additionally, the discriminative capability of ICL 4,5 and 6 may be lost due to the above stated possibility that these traits are held in common during a low ebb by depressed and nondepressed individuals alike. Consequently, this author feels that more investigation is warranted before dismissing the proposed relationship between depression and passive-dependent, self-depreciating traits. One can conclude, on the basis of this study, that the self-ascribed interpersonal traits of passivity, self-effacement and dependency do not differentiate depressed from nondepressed persons when they are presenting themselves for psychological treatment.

Another ICL scale which differentiated depressed from nondepressed samples was scale 7 , a scale labeled cooperative-over-conventional. This scale, which the author did not expect to discriminate between samples, contains items descriptive of an individual who expresses agreeable, affiliative behavior and who strives to be liked and accepted by others. It describes a general mode of peaceable, loving and brotherly behavior that approaches a cultural ideal. The fact that these traits distinguished the depressed and nondepressed samples may be alternatively explained by positing a tendency for the depressed sample to avoid the use of these terms, or, by conceiving the nondepressed sample to find these qualities self-descriptive. An interaction, or combination of these two effects is likely. In 
that there is a tendency for depressed persons to describe themselves in a negative fashion (or with the absence of positive, see Beck, 1967), there may have been an avoidance of this most positively saturated scale on the part of the depressed sample. Aiternatively, the nondepressed sample may have found these traits self-descriptive as this over-conventional mode of adjustment is often associated with anxious patients (Leary, 1957). (Note: anxiety was one of the primary chief complaints in the nondepressed sample). If the latter explanation of the results is in effect, it would render the significance of scale 7 attributable to an artifact of the makeup of the nondepressed sample and not then, a result unique to the presence or absence of depression.

The remaining ICL scale that showed some capacity to differentiate among the depressed and nondepressed sample was ICL scale 8 . The relatively smaller $F$ value associated with this variable suggests that its relationship with depression is not as strong as the previously discussed scales 2 and 7 . This result does suggest however, that the interpersonal qualities of being strong, capable, loving, parental and generally willing and able to take care of others were more frequently chosen by the depressed sample as self-descriptive than by the nondepressed sample. This self-image of being sympathetic, considerate, generous, able and willing to give to others, generally a 
responsible (even hyper-normal) loving parent is not uncommon in an individual who periodically suffers from depression. The individual characterized by these traits in extreme is so exclusively attentive to others' needs that he is out of touch with his own emotional needs. Such an individual could be conceived as rigidly entrenched in the role of the helper or rescuer and unable to allow the dependency necessary to have his own needs met. Depression would ensue when the individual has emotional needs, (perhaps as a result of situational stress or loss), not being met due to the individual's maladaptively deficient interpersonal style that does not include the capacity to be dependent on another.

In summary, in that ICL scale 2 was the most clearly differentiating variable for depression, it would appear that the interpersonal traits of independence, selfconfidence, assertiveness, self-respect, competitiveness, the ability to be businesslike or indifferent to others and a general positive self-regard are more likely to be chosen by a nondepressed individual than a depressed individual in describing themselves to a clinician on an initial visit to the clinic or office. The fact that the depressed samples' self-descriptions contained significantly less references to assertive interpersonal traits is consistent with some of the results obtained by Youngren and Lewinsohn (1980) and Brown and Goodstein (1962). 


\section{Demographic Variables and Depression}

In addition to the results pertaining to the ICL and depression, it should be noted that the demographic variable of marital status-single was found to have a significant relationship with depression when entered in the regression as a potential predictor variable along with ICL variables.

The results of the overall regression analysis indicate that there is a negative correlational relationship between the marital status-single and the incidence of depression. The strength of the relationship is indicated in the significant simple correlation, $(\underline{r}=-.30 ; \mathrm{F}=18.88$; $\mathrm{d} f=1 / 201 ; \alpha<.05)$ as well as by the primary role given "single" in the regression analysis. After knowing an individuals' score on ICL scale 2 (how assertive they perceive themselves), the accuracy of prediction of membership in a depressed or nondepressed sample is significantly increased by identifying whether the individual is single or not.

In explaining the significance of marital statussingle in the prediction of depression in this sample, the $t$ tests on the demographics between the samples is important to consider. The $t$ tests revealed that the depressed and nondepressed samples differed significantly on marital status-single. The nondepressed subject was characterized as more likely to be single as reflected in the number of married, divorced and single people in each sample. A 
previous study (Overall, 1971) indicated that individuals married once are more likely to be depressed than those with multiple marriages or never married. The distribution of marital status in this depressed sample is consistent with this previous observation.

The $t$ tests on demographic variables between samples also revealed the depressed sample to be significantly older than nondepressed sample. The direction of this difference is again consistent with previous studies (e.g. Munro, 1966) that indicate incidence of depression increasing with advancing age. Any conclusions from this study with regard to the significance of demographic variables and depression are considered with caution due to sampling procedures. The sampling process allowed any differences on depression to confound with the two settings for data collection, not allowing differences on a variable to be clearly attributable to the absence or presence of depression.

\section{Severity of Depression and the ICL}

The data do indicate there is a relationship between severity of depression and ICL scores. The multiple correlation between severity of depression and selected ICL scales was modest $(\underline{R}=.2571)$. These results indicate that approximately six percent of the variance of HRS-D scores can be accounted for by a linear combination of ICL scales 
6 and 2. However, the standard error of the predicted HRS-D scores $(\underline{\text { S.E. }}=5.16)$ and the standard deviation of the original HRS-D scores ( $\underline{\text {.D. }}=5.28)$. Thus, it would appear that the random fluctuation of HRS-D scores was not "decreased" or "controlled" by the consideration of ICL scores.

The regression equation containing ICL scales 6 and 2 has a constant value of 24.33 . This constant is less than 1 unit away from the overall mean of the HRS-D scores $(\bar{X}=$ 25.27). Our best prediction, then, using the only significant predictors (ICL 6 and 2) is very close to the overall mean of the original scores. This suggests that the regression is of little assistance in determining an individual's HRS-D score beyond using the group mean as a prediction. Given the small, though statistically reliable correlation between the ICL scales and HRS-D scores, considerable caution must be used in the interpreting of these results. Additionally, the sample used is clearly not a random sample of depressed people in the United States, thus the results may serve a useful function in suggesting research but do not establish a basis for generalizing to the general population.

of the scales $4,5,6,1$ and 2 predicted to be significant, both scales 6 and 2 were found to have a demonstrated relationship with HRS-D scores. The interpersonal traits of passive-dependency (scale 6) were found to be 
positively correlated with HRS-D scores. The more depressed a subject was on the HRS-D, the more he/she described themselves on the ICL as needy and dependent. The negative correlation of scale 2 with HRS-D, is consistent with, though not nearly as strong as findings in the depressed-nondepressed regression analysis, and implies an absence of assertive traits in the self-descriptions of subjects with higher HRS-D scores. The fact that scale 2 was significant in both the prediction of the occurrence of depression and the severity of depression increased the overall significance of the apparent relationship between self-ascribed assertive, self-respecting behaviors and depression.

One factor which may have served to reduce the magnitude of the multiple correlation obtained between ICL scales and severity of depression scores is that all of the patients were depressed, at least mildly. Thus, there was a restriction of range on the HRS-D scores. As noted earlier, it was this fact that led to the efforts to obtain a nondepressed clinical sample from another setting. Within the context of this current analysis, one can only speculate that the restriction of range may be suppressing the estimate of the correlation between interpersonal traits and severity of depression.

An alternative explanation for modest results would be that the ICL is not sensitive to differences among selfdescriptions along a continuum of depression from low-moderate 
to severe. The scoring methods employed in this study utilized gross ICL variables of octants. It could be argued that if more precise measures were used (e.g. 16ths or individual item analysis), the ICL may have proven to be a discriminative measure on severity of depression. However, it was the reasoning of this researcher that an increased number of variables would lead to decreased reliability and an overall loss of validity of the findings. That is, the more finely one scores the ICL, the fewer the number of items that contribute to the scoring of the variable, consequently, the reliability of the variable is reduced. Reduced reliability would decrease the overall validity of the findings (Kerlinger and Pedhazur, 1973). Consequently, octant variables were utilized in the analysis.

The findings further suggest that there is no definitive relationship between the demographic variables: age, sex, marital and educational status (as measured in this study) and severity of depression as measured on the HRS-D. Such nonsignificant results may be attributable to the restricted range problem discussed above or to actual variable relationships. One can conclude that demographic variables do not account for a significant amount of the variance of HRS-D scores ranging from low-moderate to severe.

In summary, it would appear that self-descriptions of interpersonal traits and data on demographic variables 
do not hold more than a modest relationship with scores on severity of depression sufficient for prediction of depression severity scores substantially more precise than the group mean. The results do suggest that the self-ascribed interpersonal traits of passive-dependency (octant 6) tend to be endorsed more frequently by individuals who are more depressed. Additionally, subjects with higher HRS-D scores tended not to endorse as self-descriptive, items referring to a self-reliant, assertive individual (octant 2). It is likely that the restricted range inherent in a sampling of depressed subjects tended to obfuscate the actual relations among the variables studied.

\section{$\underline{t}$ Test Findings}

The results of the multiple $t$ comparisons suggest that depressed and nondepressed samples' self-descriptions differ significantly in the frequency of items endorsed on scales 2,1 and 7 . The null hypothesis, Ho: $I_{D} L_{D}=I C L_{G P}$ can be rejected for the scales 2, 1 and 7 . Depressed subjects were found to less frequently endorse as self-descriptive the items in these three scales referring to selfrespect and assertiveness (scale 2), managerial and leadership traits (scale 1), and traits of conventional cooperation and affiliative behaviors (scale 7). The scales 1 and 2 were two of the six scales predicted to be significant. These results can be explained by noting the self- 
affirming and positive connotations of the traits described in these scales and the tendency of depressed persons to not describe themselves in a positive and affirmative manner (Beck, 1967). The findings of the $t$ test analysis of the ICL profiles support the findings of the regression analysis of ICL on depression as a dichotomous variable previously discussed. 
CHAPTER V

\section{SUMMARY AND CRITIQUE}

In summary, the overall hypothesis that self-descriptions of interpersonal behavior traits obtained on an initial psychological visit significantly differ between depressed and nondepressed psychiatric outpatients was generally supported. The nature of the difference lies primarily in a tendency for depressed persons to endorse less frequently than nondepressed persons items descriptive of a self-assured, self-respecting and competitive striving individual (octant 2). To a lesser extent, the general qualities of loving, affiliative behavior differentiated between the groups with the depressed group less frequently indicating these items as self-descriptive (octant 7). The specific hypotheses that $D$ and GP would differ on ICL 2 and 1 was supported while there was no support for hypothesized differences on ICL 4,5 and 6 .

The hypothesis that self-descriptions on the ICL covaries with severity of depression was not definitively supported by the data. There was an indication that traits characterized by passive-dependency were more frequently chosen (octant 6) while traits of self-reliance and 
assertiveness were less frequently chosen by individuals more severely depressed (octant 2). These findings on the severity of depression and its relationship to self-descriptions on the ICL, although not statistically strong, are significant. The results are particularly noteworthy in that the study was methodologically sound and provided results consistent with previous findings. Of the ICL scales hypothesized to significantly covary with severity of depression, predicted differences on scales 2 and 6 were supported by the data while ICL scales $1,2,4$ and 5 were not found to differ significantly on severity of depression.

The strength of the findings in the analysis of ICL variables and the incidence of depression can be diminished somewhat by inherent methodological flaws in the study. These deficiencies lie primarily in the sampling procedures. One of the deficiencies is the choice of two distinct settings for obtaining data on the depressed and nondepressed samples. The second shortcoming has to do with the screening procedures used for the two groups.

With regard to the setting, there is a fundamental problem of having gathered data on nondepressed subjects in a different setting from where the depressed subject data was gathered. Although the conditions were similar (the ICL was administered as part of an intake battery of tests on an initial visit) and assured similar test-taking sets, there are distinct differences. The data on the nondepressed 
sample was gathered at a university psychological clinic that served the general community (as opposed to the university counseling center, which primarily addresses the needs of the student community). The depressed subjects were tested in a private clinician's office in a medical complex .

The use of these distinctly different settings for data collection decreased the likelihood that the investigator sampled from the same population of psychiatric outpatients and introduced a confound between depression and setting. Consequently, any inferences from the results are limited as it is impossible to completely separate differences on the ICL due to setting and those due to the variable of interest, depression. Importantly however, statistical control of "setting" through examination of the correlations between the significant ICL variables and significant demographic variables (those associated with "setting") allow some distinction to be made between the influence of depressed/nondepressed and "setting".

An additional flaw in this study was in the selection and screening of nondepressed subjects. Selection was limited to existing data banks which were limited and did not provide consistent data on each subject. For membership in the nondepressed sample, the dual criteria of chief complaint and MMPI profile was used. Although invalid MMPI profiles were screened out, the reliability of a selection 
procedure relying so heavily on one psychometric measure can be questioned. The theoretical assumption of the existence of a truly nondepressed psychiatric population is also questionable as depression seems to be somewhat ubiquitous and is present to varying degrees in virtually al1 individuals motivated to seek psychological services. More thorough screening of nondepressed subjects would have increased the likelihood of having distinct depressed and nondepressed samples.

A final element of this research that potentially decreased the likelihood of obtaining significant results was the choice of ICL octants as variables. It may be argued that further reduction to sixteenths or individual items would have yielded results allowing a more definitive distinction between the depressed and nondepressed groups. However, it was the reasoning of this researcher that increased dependent variables would decrease the reliability and overall validity of the results. For this reason, and for interpretability of the results, octants were chosen as the dependent variables.

\section{Conclusions}

In conclusion, the strongest findings were in the regression of ICL variables onto depression expressed as a dichotomous variable reflecting either the presence or absence of depression and measured by various diagnostic 
criteria. The relative absence of interpersonal traits implying positive self-esteem and assertiveness in the self-descriptions of depressed persons was the most significant difference between the depressed and nondepressed groups' ICL profiles.

Methodological shortcomings are evident in sampling procedures resulting in a perfect confound between depression and setting. With respect to this shortcoming however, the significance of the relationship between self-ascribed assertive traits and depression is retained if one considers: 1) the indication of a capacity for ICL scale 2 to differentiate among severity of depression on the HRS-D as well as differentiate between depressed and nondepressed groups; 2) that assertive behaviors have a previously demonstrated relationship to depression; and 3) the correlations between ICL scale 2 and the demographic variables found to differ between groups was minimal, suggesting that the differences on scale 2 is actually with reference to the presence or absence of depression.

Future research into the nature of self-descriptions and depressive disorders is needed to more accurately define the self-perceptions of interpersonal traits of a depressed person. Problem areas that could be addressed include, the discrepancy factor between subjective and objective perceptions, the influence of communicative intentions in self-report data and, sampling procedures 
that allowed demographically and clinically comparable depressed and nondepressed groups. 


\section{REFERENCES}

Abraham, K. Notes on the psychoanalytic investigation and treatment of manic-depressive insanity and allied conditions, (1911). In, Selected Papers on Psychoanalysis. New York: Basic Books, 1960, pp. 137156.

Abraham, K. The first pregenital stage of the libido, (1916). In, Selected Papers on Psychoanalysis. New York: Basic Books, 1960, pp. 248-279.

Abraham, K. A short study on the development of the libido, (1924). In, Selected Papers on Psychoanalysis.

New York: Basic Books, 1960, pp. 418-501.

Bateson, G., Jackson, D. D., Haley, J. and Weakland, J. Toward a theory of schizophrenia. Behavioral Science. 1956,1 , pp. 251-261.

Bech, P., Gram, L. F., Dein, E., Jacobsen, O., Vitger, J., and Bolwig, T. G. Quantitative rating of depressive states. Acta Psychiatrica Scandinavica, 1975, 51, pp. $161-170$.

Beck, A. T. Depression. Philadelphia: University of Pennsylvania Press, 1967.

Bemporad, J. New views on the psychodynamics of the depressive character. In, Arieti, S. (Ed.), World Biennial of Psychiatry and Psychotherapy. New York: Basic Books Inc., 1971, Vol. 1, pp. 219-243.

Bibring, E. The mechanism of depression. In, Gaylin, W. (Ed.), The Meaning of Despair. New York: Science House, Inc., 1968, Chap. 7.

Black, J. D. Adjectives associated with various MMPI codes. In Welsh, G. S. and Dahlstrom, W. G. (Eds.), Basic Readings on the MMPI in Psychology and Medicine. Minneapolis: University of Minnesota Press, 1969 , pp. 151-172.

Bodin, A. M., and Geer, J.N. Association responses of depressed and nondepressed patients to words of three hostility levels. Journal of Personality, $1965,33(3), 392-408$. 
Bonime, W. The psychodynamics of neurotic depression. In Arieti, S. (Ed.), American Handbook of Psychiatry, Vol. 3. New York: Basic Books, 1966.

Briar, S., and Bieri, J. A factor analytic and trait inference study of the Leary Interpersonal Check1ist. Journal of Clinical Psychology, 1963, 19, pp. $193-198$.

Brown, R. A., and Goodstein, L. A. Adjective checklist correlates of extreme scores on the MMPI-D scale. Journal of Clinical Psychology, 1962, 18, 477-481.

Carrol1, B., Fielding, J., and Blashki, T. Depressive rating scales. Archives of General Psychiatry, $1973, \underline{28}$, pp. 361-366.

Chodoff, P. The depressive personality. Archives of Genera1 Psychiatry, 1972 , 27, pp. 666-673.

Coyne, J. D. Toward an interactional description of depression. Psychiatry, 1976, 39, pp. 14-27.

Dunn, 0. J. Multiple comparisons among means. Journal of the American Statistical Association, $1 \overline{961,56}$, pp. 52-64.

Ferster, C. A functional analysis of depression. American Psychologist, 1973, 10, pp. 857-860.

Galton, L. When you don't know what ails you. Parade Magazine, 1979, December 9, pp. 7-9.

Gough, H. G. Reference Handbook for the Gough Adjective Check-List. Berkeley: University of California Institute of Personality Assessment and Research, 1955 (mimeo).

Gravitz, M. A. Self-described depression and scores on the MMPI-D scale in normal subjects. Journal of Projective Techniques and Personality Assessment, 1968, 32(1), 88-91.

Grinker, R. Reception of communications by patients in depressive states. Archives of General Psychiatry, 1964,10 , pp. 576-580.

Haley, J. Changing Families; A Family Therapy Reader. New York: Grune and Stratton, 1971. 
Hamilton, M. A rating scale for depression. Journal of Neurology and Neurosurgical Psychiatry, $1960, \underline{23}$, pp. 56-63.

Hathaway, S. R., and McKinley, J. C. A multiphasic personality schedule (Minnesota): I. Construction of the schedule. Journal of Psychology, 1940, 10, pp. $249-254$.

Hathaway, S. R., and McKinley, J. C. A multiphasic personality schedule (Minnesota): III. The measurement of symptomatic depression. Journa1 of Psychology, 1942, 14, pp. 73-84.

Heilbrun, A. B. Validation of a need scaling technique for the Adjective Check List. Journal of Consulting Psychology, 1959, 23, pp. 347-351.

Hogsett, S. G. A method to increase the validity of Interpersonal Checklist "self" ratings. Dissertation Abstracts Internationa1, 1972, Sept., V $39(3-A)$, 1021.

Kenesevich, J. W. The validity of the Hamilton Rating Scale for Depression. British Journal of Psychiatry, 1977,131 , pp. 49-52.

Kerlinger, F. N., and Pedhazur, E. J. Multiple Regression in Behavioral Research. New York: Holt, Rinehart and Winston, Inc, 1973 .

Kirk, R. E. Experimental Design: Procedures for the Behavioral Sciences. Belmont, California: Brooks Cole Publishing Co., 1968.

LaForge, R., Leary, T. F., Naboisek, N., Coffey, N. S., and Freedman, M. B. The interpersonal dimension of personality: II. An objective study of repression. Journal of Personality, 1954, 23, pp. 129-153.

LaForge, R., and Suczek, R. F. The interpersonal dimension of personality: III. An interpersonal checklist. Journal of Personality, 1955, 24, pp. 94-112.

LaForge, R. Using the ICL, 1976. Available 83 Homestead Bivd., Mill Valley, California.

Leary, T. F. Interpersonal Diagnosis of Personality.

Lewinsohn, P. M., and Shaffer, M. The use of home observations as an integral part of the treatment of depression: Preliminary report and case studies. Journal of Consulting and Clinical Psychology, 1971,37, pp. 87-94. 
Lewinsohn, P. M., Weinstein, M. S., and Alper, T. A behaviorally oriented approach to the group treatment of depressed persons: A methodological contribution. Journal of Clinical Psychology, 1970, 26, pp. $525-\overline{532}$.

Lewinsohn, P. M., Weinstein, M. S., and Shaw, D. A. Depression: A clinical research approach. In D. R. Rubin and C. M. Frank (Eds.), Advance in Behavioral Therapy. New York: Academic Press, 1969.

Libet, J., and Lewinsohn, P. M. The concept of social skill with special reference to the behavior of depressed persons. Journal of Consulting and Clinical Psychology, 1973(a), 40, pp. 304-312.

Libet, J., Lewinsohn, P. M., and Javorek, F. The construct social skill: An empirical study of several measures on temporal stability, internal structure, validity and situational generalizability. Unpub1ished Manuscript, University of Oregon, Eugene, Oregon, 1973 (b).

Mager, R., and Pipe, P. Analyzing Performance Problems. Belmont, California: Fearon Publishers, 1970, Ch. 11.

Malamud, M., Sands, G. L., and Malamud, I. The involutional psychoses: A sociopsychiatric study. Psychosomatic Medicine, $1941, \underline{3}$, pp. 410-426.

McDonald, R. L. Leary's overt interpersonal behavior: A validation attempt. Journal of Social Psychology, 1968, 74, pp. 259-264.

Meehl, S. R., and Hathaway, P. L. The MMPI. In, Military Clinical Psychology, Dept of the Army Technical Manual, TM 8:242. Dept of the Air Force Manual, AFM 160-145. Washington, D.C.: U.S. Government Printing Office, 1951 .

Overal1, J. E. Associations between marital history and the nature of manifest psychopathology. Journal of Abnorma1 Psychology, 1971, 78, pp. 213-221.

Palmer, H. D., and Sherman, S. H. Involutional melancholia process. Archives of Neurological Psychiatry, 1938, 40, pp. $762-788$.

Rado, S. Psychodynamics of depression from the eitiologic point of view. In, W. Gaylin (ed.), The Meaning of Despair. New York: Science House, Inc., 1968, Ch. 5. 
Rado, S. The Problem of melancholia. International Journal of Psychoanalysis, 1928, , pp. 420-438.

Ruesch, J. Therapeutic Communication. New York: Norton Press, 1962 .

Salzman, L. The Obsessive Personality. New York: Science House, 1968 .

Satir, V. M. Conjoint Family Therapy; A Guide to Theory and Technique. Palo Alto, California: Science and Behavior Books, 1964 .

Seligman, M. Depression and learned helplessness. In, R. J. Friedman and M. M. Katz (Eds.), The Psychology of Depression: Contemporary Theory and Research. New York: John Wiley and Sons, 1974.

Sullivan, H. S. The Interpersonal Theory of Psychiatry. New York: Norton, 1953 .

Titley, W. B. Presychotic personality of patients with involutional melancholia. Archives of Neurological Psychiatry, 1936, 36, pp. 19-33.

Weissman, M. M., and Payke1, E. S. The Depressed Woman: A Study of Social Relationships. Chicago: University of Chicago Press, 1974.

Wolpe, J. Neurotic depression: experimental analog, clinical syndromes, and treatment. American Journal

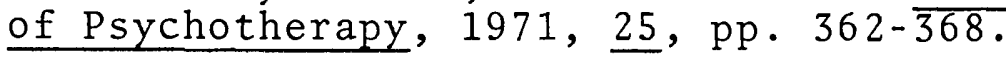

Youngren, M. A., and Lewinsohn, P. M. The functional relation between depression and interpersonal behavior. Journal of Abnormal Psychology, 1980, 89, pp. 333-341.

Youngren, M. A., Zeiss, A. M., and Lewinsohn, P. M. The Interpersonal Events Schedule. Mimeograph, University of Oregon, Eugene, Oregon, 1975. 
APPENDIX A

INTERPERSONAL CHECK LIST

ILLUSTRATING THE CLASSIFICATION OF INTERPERSONAL BEHAVIORS INTO 16 VARIABLE CATEGORIES

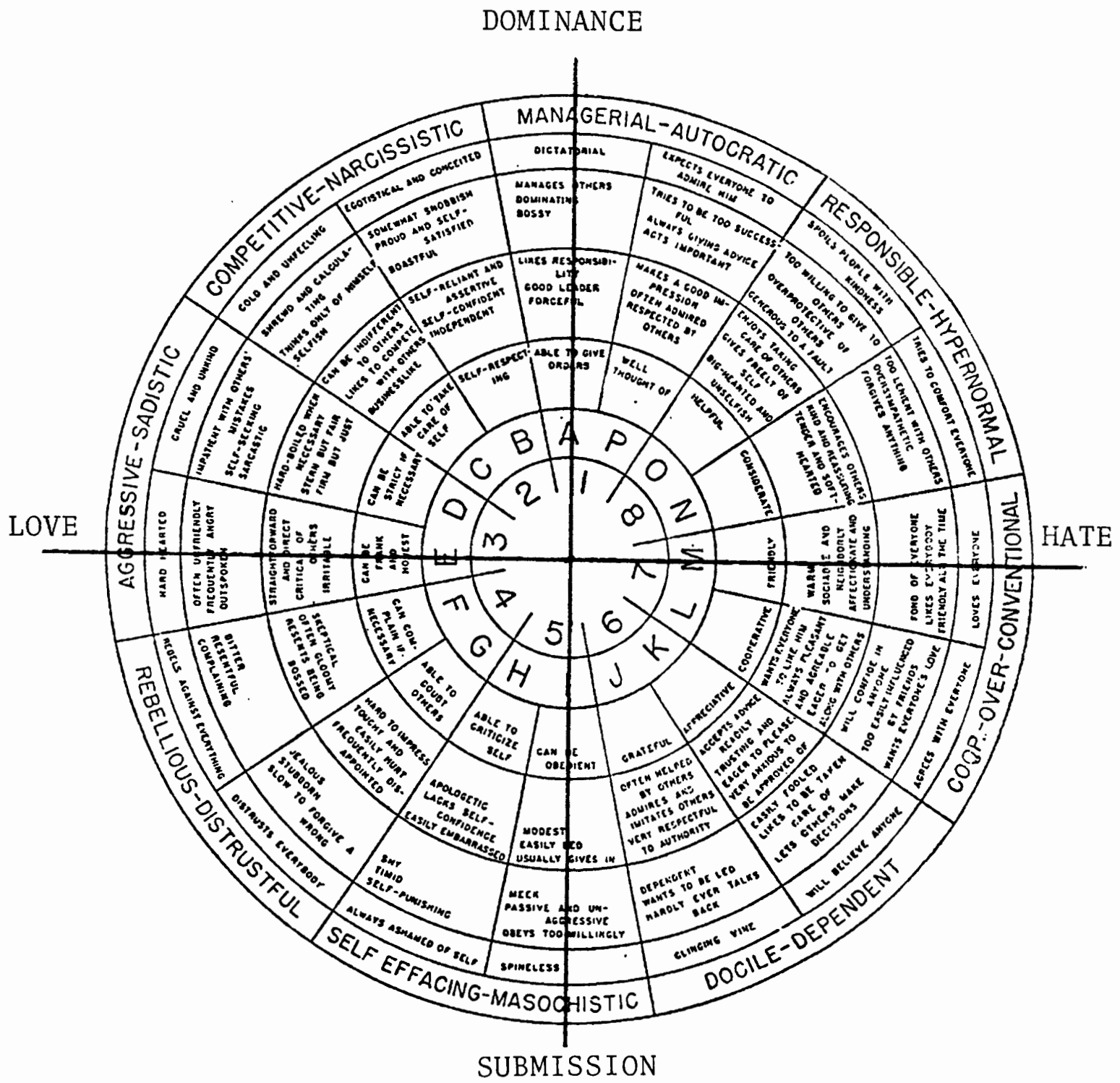



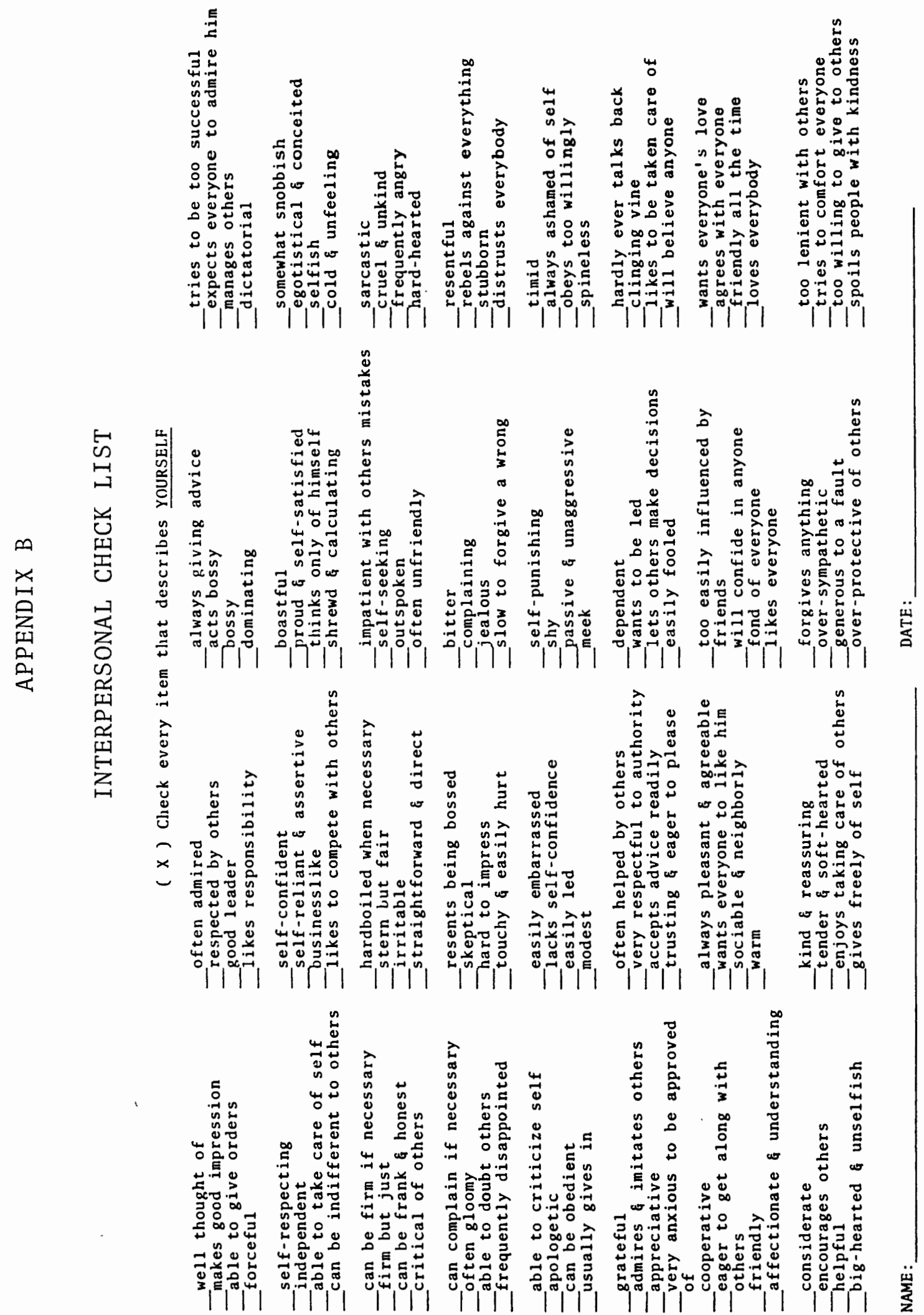

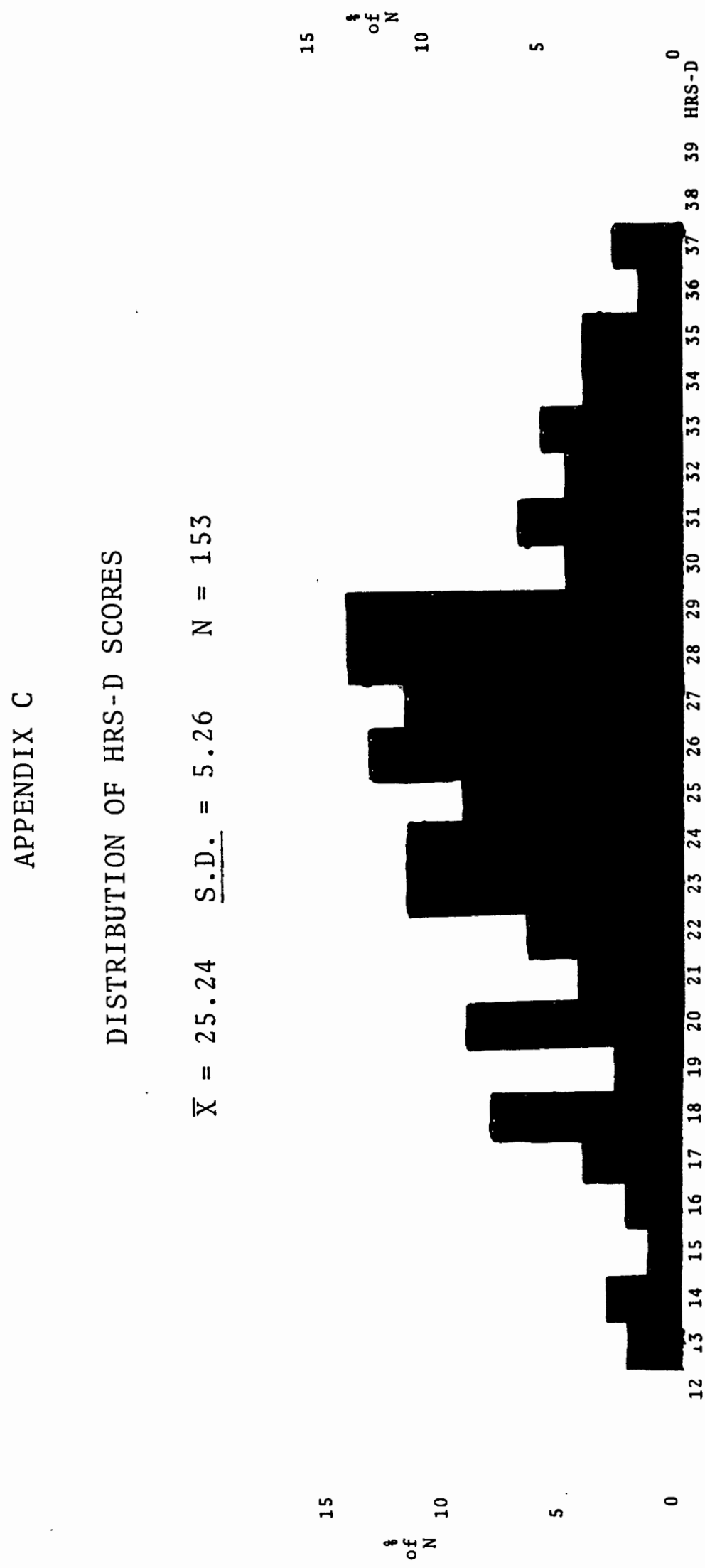